\title{
Single-molecule fluorescence in-situ hybridization reveals that human SHANK3 mRNA expression varies during development and in autism-associated SHANK3 heterozygosity
}

\author{
Samuel E. Taylor ${ }^{1,2}$, Ruth D. Taylor ${ }^{1,2}$, Jack Price ${ }^{2,3}$ and Laura C. Andreae $e^{1,2^{*}}$
}

\begin{abstract}
Background: Deletions and mutations in the SHANK3 gene are strongly associated with autism spectrum disorder and underlie the autism-associated disorder Phelan-McDermid syndrome. SHANK3 is a scaffolding protein found at the post-synaptic membrane of excitatory neurons.

Methods: Single-molecule fluorescence in-situ hybridization (smFISH) allows the visualization of single mRNA transcripts in vitro. Here we perform and quantify smFISH in human inducible pluripotent stem cell (hiPSC)-derived cortical neurons, targeting the SHANK3 transcript.

Results: Both smFISH and conventional immunofluorescence staining demonstrated a developmental increase in SHANK3 mRNA and protein, respectively, in control human cortical neurons. Analysis of single SHANK3 mRNA molecules in neurons derived from an autistic individual heterozygous for SHANK3 indicated that while the number of SHANK3 mRNA transcripts remained comparable with control levels in the cell soma, there was a 50\% reduction within neuronal processes, suggesting that local, dendritic targeting of SHANK3 mRNA may be specifically affected in SHANK3 haploinsufficiency.

Conclusion: Human SHANK3 mRNA shows developmentally regulated dendritic localization in hiPSC-derived neurons, which is reduced in neurons generated from a haploinsufficient individual with autism. Although further replication is needed, given the importance of local mRNA translation in synaptic function, this could represent an important early abnormality.
\end{abstract}

Keywords: Single-molecule fluorescence in-situ hybridization, mRNA, SHANK3, ProSAP2, Human inducible pluripotent stem cell, Autism, Autism spectrum disorder

\section{Background}

Haploinsufficiency for the SHANK3/ProSAP2 gene is believed to be one of the most common monogenic causes of autism spectrum disorder (ASD), accounting for approximately $0.5 \%$ of cases [1]. Deletions or mutations in SHANK3 underlie the autism-associated neurodevelopmental disorder

\footnotetext{
*Correspondence: laura.andreae@kcl.ac.uk

${ }^{1}$ Centre for Developmental Neurobiology, Institute of Psychiatry, Psychology and Neuroscience, King's College London, London SE1 1UL, UK

${ }^{2}$ MRC Centre for Neurodevelopmental Disorders, King's College London,

London, UK

Full list of author information is available at the end of the article
}

Phelan-McDermid syndrome (PMS) [2, 3] and have also been strongly associated with non-syndromic ASD [4-6]. The SHANK proteins are synaptic scaffolding proteins that are enriched at the post-synaptic density of excitatory synapses, where they interact with other post-synaptic density proteins to influence synapse structure and function [7-9]. Studies in both mice and human cell lines where SHANK3 is deleted have revealed multiple deficits in excitatory synapse function, as well as intrinsic neuronal abnormalities $[10,11]$. However, although there is evidence that overall levels of SHANK3 mRNA are reduced in human inducible

(c) The Author(s). 2018 Open Access This article is distributed under the terms of the Creative Commons Attribution 4.0 International License (http://creativecommons.org/licenses/by/4.0/), which permits unrestricted use, distribution, and 
pluripotent stem cell (hiPSC)-derived neurons from patients with heterozygous SHANK3 deletions and PMS [12], little is known regarding the local expression of SHANK3 mRNA in human neurons. While shank3 mRNA has been detected in the neuropil of hippocampal CA1 pyramidal neurons in rodents, presumably corresponding to dendrites [13, 14], no detailed analysis has been done in humans. We therefore utilized a single-molecule fluorescent in-situ hybridization (smFISH) approach in neurons derived from hiPSCs to examine SHANK3 expression in more detail.

Single-molecule fluorescent in-situ hybridization (smFISH) uses a combination of multiple, small, fluorescently labelled probes, each probe complementary to a different region along the nucleic acid of interest, to increase detection sensitivity and allow the visualization of single nucleic acid molecules. This technique has been used to detect single RNA molecules in a wide range of cells and organisms, from yeast [15] to mouse intestinal stem cells [16], and more recently in humans to detect expanded repeats in polyglutamine diseases [17] and long non-coding RNAs in fibroblasts and HeLa cells [18]. Here, we designed a combination of 48 unique smFISH probes to detect human SHANK3 mRNA transcripts. We used hiPSC-derived neurons from a control iPSC line [19] which were differentiated to a cortical fate using a well-validated protocol [20]. We quantified both SHANK3 mRNA and protein levels in the cell soma and in neuronal processes at different developmental time points as the neurons mature in culture. Finally, to investigate whether there are compartment specific reductions in SHANK3 mRNA in the context of SHANK3 haploinsufficiency, we examined the localization of single SHANK3 mRNA molecules in neurons derived from an individual with autism (but not PMS) with a microdeletion affecting only the SHANK3 gene $[19,21]$.

\section{Methods \\ Cell culture}

Human inducible pluripotent stem cell (hiPSC) lines were generated from keratinocytes using a lentiviral construct [19]. Neural induction to produce cortical neuronal progenitors was performed using a modified dual SMAD inhibition protocol $[20,21]$. SHANK $3^{+/-}$hiPSCs were generated from a 4-year-old male with a deletion on chromosome 22q extending from the third intron of SHANK3 through to past the $3^{\prime}$ end of the gene [19]. All time points mentioned begin from the point of final plating as neuronal progenitors. All consumables were purchased from Gibco unless otherwise stated.

Prior to plating, Grid-500 plates (ibidi $\mathrm{GmbH}$ ) were coated with poly-D-lysine 70-150 kDa (PDL, $5 \mu \mathrm{g} / \mathrm{ml}$; Sigma) incubated at $37{ }^{\circ} \mathrm{C}$ for $6 \mathrm{~h}$, followed by three washes with PBS and laminin coated overnight $(10 \mu \mathrm{g} / \mathrm{ml})$ at $37{ }^{\circ} \mathrm{C}$. Neuronal cultures were thawed in rho kinase (ROCK) inhibitor $\left(\begin{array}{ll}10 & \mu \mathrm{M}\end{array}\right)$ and $N$-((3,5-difluorophenyl)acetyl)-L-alanyl-2-phenylglycine-1,1-dimethylethyl ester (DAPT, $10 \mu \mathrm{M})$ in hiPSC media $(2 \mathrm{mM}$ glutamax, $50 \mathrm{mg} / \mathrm{ml}$ penicillin, $50 \mathrm{mg} / \mathrm{ml}$ streptomycin, in Neurobasal medium supplemented with B27 following the manufacturer's instructions), centrifuged at $160 \times g$ for $5 \mathrm{~min}$ and the supernatant re-suspended in ROCK inhibitor media. Human cortical neuronal progenitors were plated at 312,000 cells $/ \mathrm{cm}^{2}$ and incubated at $37^{\circ} \mathrm{C}$. At 1 and 4 days in vitro (DIV), half of the media was replaced with DAPT $(10 \mu \mathrm{M})$ in hiPSC media. At 7 DIV, half of the media was replaced with brain-derived neurotrophic factor (BDNF, $10 \mathrm{ng} / \mathrm{ml}$; PeproTech) in hiPSC media and rat cortical glia coverslips were placed inverted onto the neuronal cultures. Thereafter, half of the culture media was replaced with fresh BDNF media twice a week.

To produce rat cortical glia coverslips, rat cortical glial cells were generated according to the method described by Kaech and Banker [22]. Embryonic day 18 Sprague Dawley rats were obtained from pregnant dams purchased from Charles River. Briefly, rat cortices were triturated in trypsin-EDTA and grown in DMEM-based glial media $(2.4 \mathrm{mg} / \mathrm{ml}$ glucose, $50 \mathrm{mg} / \mathrm{ml}$ penicillin, $50 \mathrm{mg} / \mathrm{ml}$ streptomycin, $10 \%$ heat-inactivated horse serum) and plated on pre-coated $30-70 \mathrm{kDa}$ PDL ( $5 \mu \mathrm{g} / \mathrm{ml})$ T75 flasks at 100,000 cells $/ \mathrm{cm}^{2}$. Rat glia were then incubated for 2 weeks at $37{ }^{\circ} \mathrm{C}$ with growth media replaced twice a week. Glia were then passaged with trypsin-EDTA for 5 min at $37{ }^{\circ} \mathrm{C}$, and plated on to $70-150 \mathrm{kDa}$ PDL-coated $(5 \mu \mathrm{g} / \mathrm{ml})$ glass coverslips with paraffin wax pedestals at $100,000 \mathrm{cells} / \mathrm{cm}^{2}$. Glial coverslips were then incubated for 1 week $\left(37^{\circ} \mathrm{C}\right)$ before co-culturing with hiPSC-derived neuron plates.

\section{Immunofluorescence}

Immunofluorescence was carried out as described previously [23]. All consumables were purchased from Gibco unless otherwise stated. Briefly, cells were fixed in $4 \%$ paraformaldehyde with $10 \mathrm{mg} / \mathrm{ml}$ sucrose for $15 \mathrm{~min}$, permeabilized in $0.01 \%$ saponin (Sigma) for $5 \mathrm{~min}$, blocked in 3\% bovine serum albumin (BSA-block; Sigma) for $30 \mathrm{~min}$ and incubated overnight in primary antibodies diluted in blocking solution at $4{ }^{\circ} \mathrm{C}$.

The primary antibodies used were rabbit-anti-SHANK3 (1:500; Atlas Ab), mouse IgG1-anti-GFAP (1:500; Millipore) and mouse IgG1-anti-MAP2 (1:500; Sigma). Cells were then washed in PBS before incubation in secondary antibodies for $30 \mathrm{~min}$ at room temperature. The secondary antibodies used were donkey-anti-mouse Alexa Fluor 568 and 647 (1:1000) and donkey-anti-rabbit Alexa Fluor 488 (1:1000). Nuclear DAPI staining was also carried out. Images were acquired with an Olympus FV1000 confocal 


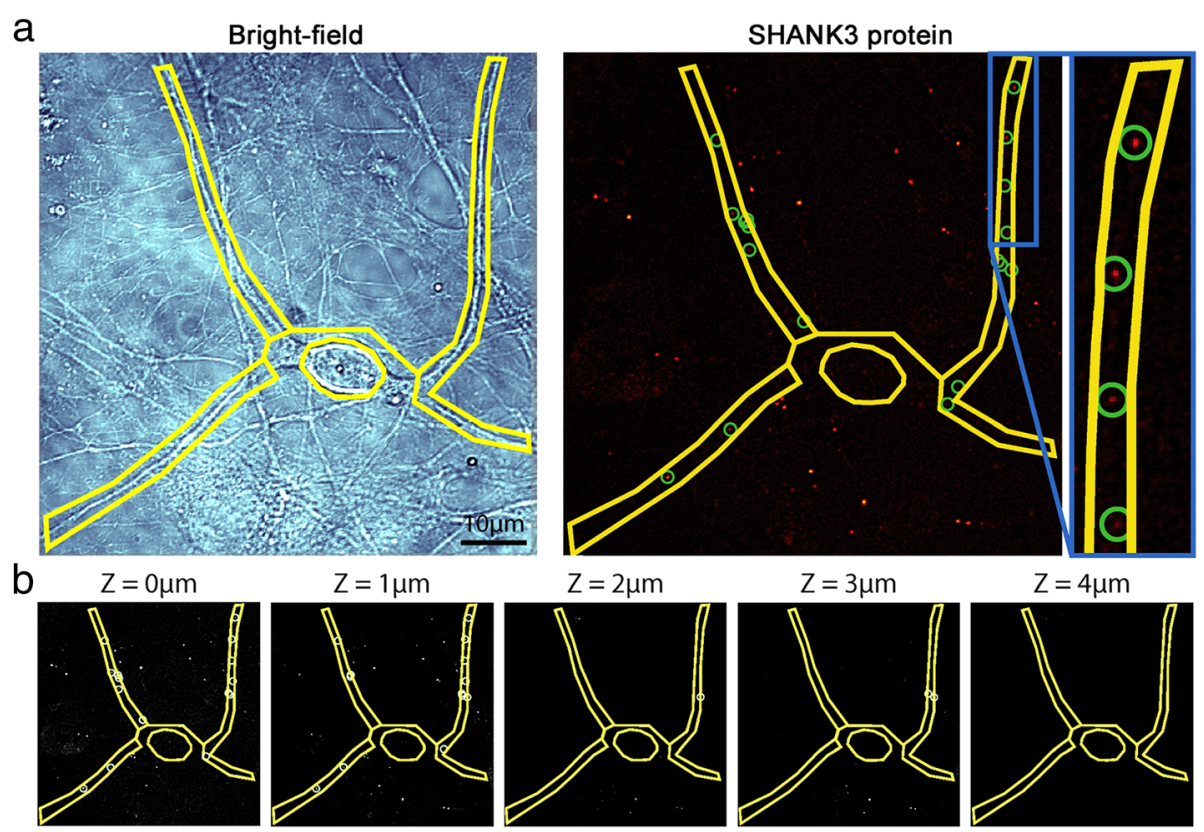

Fig. 1 SHANK3 mRNA and protein puncta selection in hiPSC-derived cortical neurons. a Left panel: bright-field images used to manually outline cell body and neuronal processes. Right panel: puncta (circled) detected using automated algorithm, defined by intensity and size threshold. Only puncta lying within outlined areas included. b Puncta detected at each plane (1- $\mu$ m intervals) per Z-stack. SHANK3 SH3 and multiple ankyrin repeat domains 3

microscope using the Fluoview software and a $60 \times$ oil immersion objective (1.4 numerical aperture).

\section{Single-molecule fluorescence in-situ hybridization}

Single-molecule fluorescence in-situ hybridization (smFISH) was carried out according to the Stellaris RNA smFISH protocol (Bioscience Technologies). All solutions used were made up using nuclease-free water and consumables purchased from Ambion unless otherwise stated. Growth medium was initially aspirated from the neuronal culture dishes and the cells washed in PBS. Cells were then fixed in $4 \%$ formaldehyde for $10 \mathrm{~min}$ at room temperature and washed twice in PBS, followed by 1 -h incubation at $37^{\circ} \mathrm{C}$ in $70 \%$ ethanol. Wash buffer (10\% deionized formamide) in $2 \times$ saline-sodium citrate (SSC) was then added for 2-5 min at room temperature followed by 1:100 SHANK3 mRNA smFISH probe in hybridization buffer (10\% deionized formamide, $0.1 \mathrm{~g} / \mathrm{ml}$ dextran sulfate; Millipore) in $2 \times$ SSC and incubated in the dark within a humidity chamber for $16 \mathrm{~h}$ at $37{ }^{\circ} \mathrm{C}$. The custom SHANK3 smFISH mRNA probe (ST_SHANK3, Rprobes w/Quasar 570, Custom Stellaris smFISH; Biosearch Technologies) consisted of 48 fluorescently labelled probes complementary to different regions of the SHANK3 mRNA transcript. Each probe was 20 nucleotides in length. Cells were then incubated in wash buffer for $30 \mathrm{~min}$ at room temperature, washed twice in $2 \times$ SSC and stored in $2 \times \mathrm{SSC}$ at $4{ }^{\circ} \mathrm{C}$. Images were acquired as already described.

\section{SHANK3 mRNA and protein quantification}

The number of SHANK3 mRNA and protein puncta was quantified within the cell body and processes of hiPSCderived neurons using the FISHquant software custom MATLAB script (FISH-quant v2c, MATLAB package [24]). Bright-field images were used to outline both the neuronal cell body and processes, and their respective areas calculated (Fig. 1). Bright-field images were used instead of immunofluorescence images as smFISH could not be performed in combination with immunofluorescence without diminishing the smFISH signal. Puncta within the outlined areas of the bright-field images were counted at each layer of the $Z$-stack and the total number of puncta summed. A set of parameters including puncta size, pixel intensity and distance between puncta was used to minimize the selection of false-positive puncta. A region of background was analysed as a further control to the puncta selection parameters. Average puncta density was then calculated for each region.

\section{Results}

SHANK3 protein and mRNA expression within hiPSCderived neurons

Firstly, we used immunofluorescence staining to confirm SHANK3 protein expression in hiPSC-derived cortical neurons. Co-labelling with the dendritic marker MAP2 indicated SHANK3 expression localized to dendrites and was not present at the cell body (Fig. 2a). SHANK3 expression also co-localized with the excitatory postsynaptic 
a

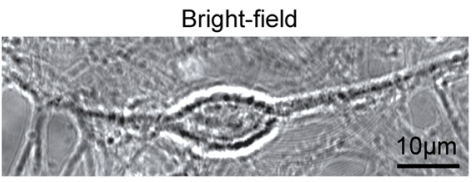

MAP2

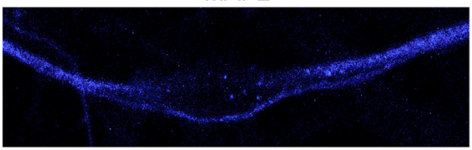

b

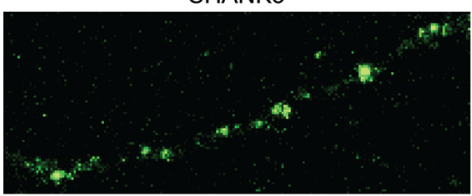

PSD95

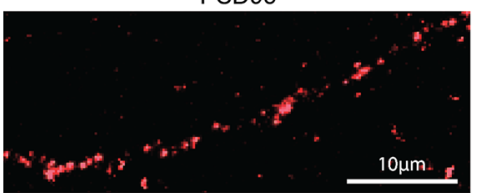

C

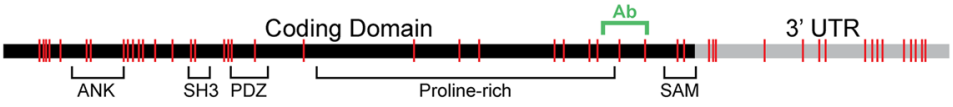

d Bright-field

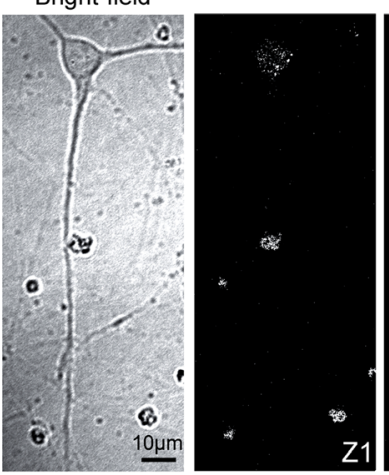

e

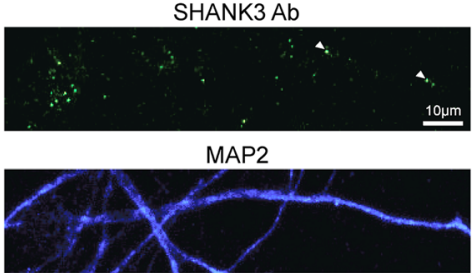

SHANK3 Protein

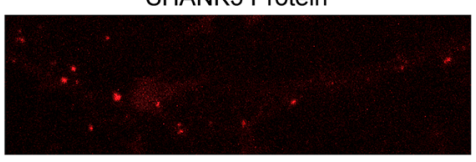

Composite

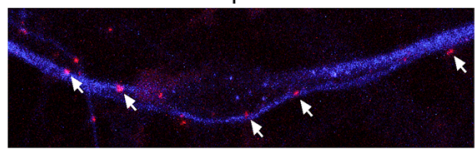

Synapsin

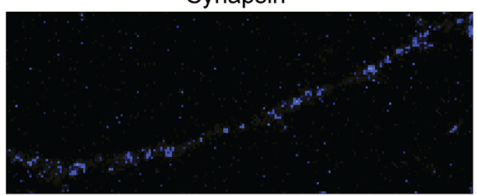

Composite

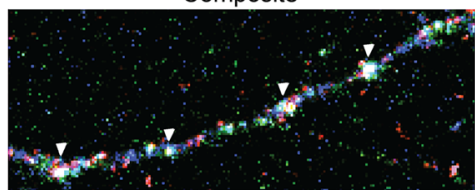

SHANK3 mRNA

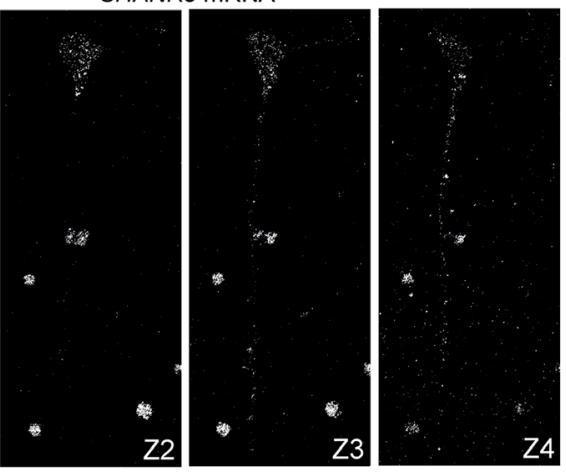

SHANK3 FISH

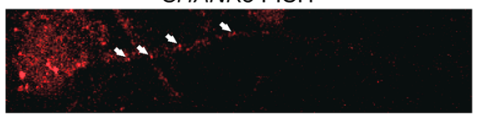

Merged

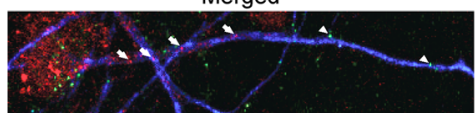

Fig. 2 SHANK3 mRNA and protein labelling and co-localization in hiPSC-derived neurons. a Immunofluorescence labelling of SHANK3 protein (red) in MAP2-positive dendrites (blue) of hiPSC-derived neurons. Arrows mark co-localization of SHANK3 protein. $\mathbf{b}$ SHANK3 (green) co-localizes with the pre-synaptic marker synapsin (blue) and post-synaptic marker PSD95 (red). Arrowheads mark co-localization of SHANK3 protein. c Schematic illustrating SHANK3 mRNA. Vertical red lines indicate complementary binding sites for smFISH probes along both coding domain and 3'-UTR. SHANK3 antibody binding site marked green. $\mathbf{d}$ Representative Z-stack of single SHANK3 mRNA transcripts labelled by SmFISH in 51 DIV hiPSC-derived neurons. SHANK3 mRNA localized to cell body and processes in hiPSC-derived neurons. e Combined SHANK3 mRNA and protein labelling in 49-DIV hiPSC-derived neuron. White arrowheads label SHANK3 protein puncta. White arrows label SHANK3 mRNA puncta. Ab antibody, FISH fluorescence in-situ hybridization, MAP2 microtubule-associated protein 2, SHANK3 SH3 and multiple ankyrin repeat domains 3, UTR untranslated region 
marker PSD95, confirming that the SHANK3 labelling was specific to excitatory synapses (Fig. 2b). We then went on to examine SHANK3 mRNA expression in hiPSC-derived neurons using single-molecule fluorescent in-situ hybridization (smFISH). A total of 48 smFISH unique probes were designed to bind to complementary sites located within both the SHANK3 mRNA coding region and 3'-untranslated region (3'-UTR) (Fig. 2c). Confocal $Z$-stack images were taken $0.5 \mu \mathrm{m}$ apart to retain high resolution with clear identification of individual puncta at each slice. SHANK3 mRNA puncta were clearly visible in both cell soma and neuronal processes neurons throughout the $Z$-stack (Fig. 2d), although SHANK3 mRNA and protein puncta did not co-localize (Fig. 2e).

\section{Developmental regulation of SHANK3 protein and mRNA expression}

In order to determine the in-vitro timescale for synapse formation and neuronal maturation in our hiPSC-derived neurons, we carried out SHANK3 protein immunofluorescence staining at 1 DIV, 28 DIV, and 115 DIV (Fig. 3a, b). SHANK3 protein expression was not observed within neuronal cell bodies (Fig. 3c) and therefore SHANK3 protein puncta were only quantified within neuronal processes. We found that SHANK3 protein expression within neuronal processes significantly increased with age. The mean
SHANK3 protein puncta density progressively increased from 0.0046 puncta/ $100 \mu \mathrm{m}^{2}$ at 1 DIV $(n=3)$ to 0.1649 puncta $/ 100 \mu \mathrm{m}^{2}$ at $28 \mathrm{DIV}(n=4)$ and 0.5088 puncta $/ 100$ $\mu \mathrm{m}^{2}$ at 115 DIV $(n=5) \quad(p<0.005$ at 1 DIV vs 115 DIV, Kruskal-Wallis test with Dunn's multiple-comparison post test). Similarly, when we examined SHANK3 mRNA expression with smFISH (at 1 DIV and 99 DIV), we found that this increased with neuronal age in both the cell body and in processes (Fig. $4 \mathrm{a}-\mathrm{C}$ ). For neuronal cell bodies, the mean SHANK3 mRNA puncta density significantly increased from 0.5039 puncta/100 $\mu^{2}$ at 1 DIV $(n=17)$ to 2.412 puncta $/ 100 \mu \mathrm{m}^{2}$ at $99 \operatorname{DIV}(n=11)(p<0.0001)$. For neuronal processes, the mean SHANK3 mRNA puncta density significantly increased from 0.0392 puncta $/ 100 \mu \mathrm{m}^{2}$ at 1 DIV $(\mathrm{n}=17)$ to 0.2737 puncta/100 $\mu^{2}$ at 99 DIV $(\mathrm{n}=11)(p<0.0001$, unpaired $t$ test $)$. These results confirmed our expectations that both SHANK3 mRNA and protein would increase with neuronal maturation as synapses are progressively formed.

\section{Reduction in SHANK3 mRNA expression in neurons derived from an individual with ASD and SHANK3 haploinsufficiency restricted to neuronal processes}

We then asked whether the number or localization of SHANK3 mRNA molecules might be affected in the context of SHANK3 haploinsufficiency. An overall

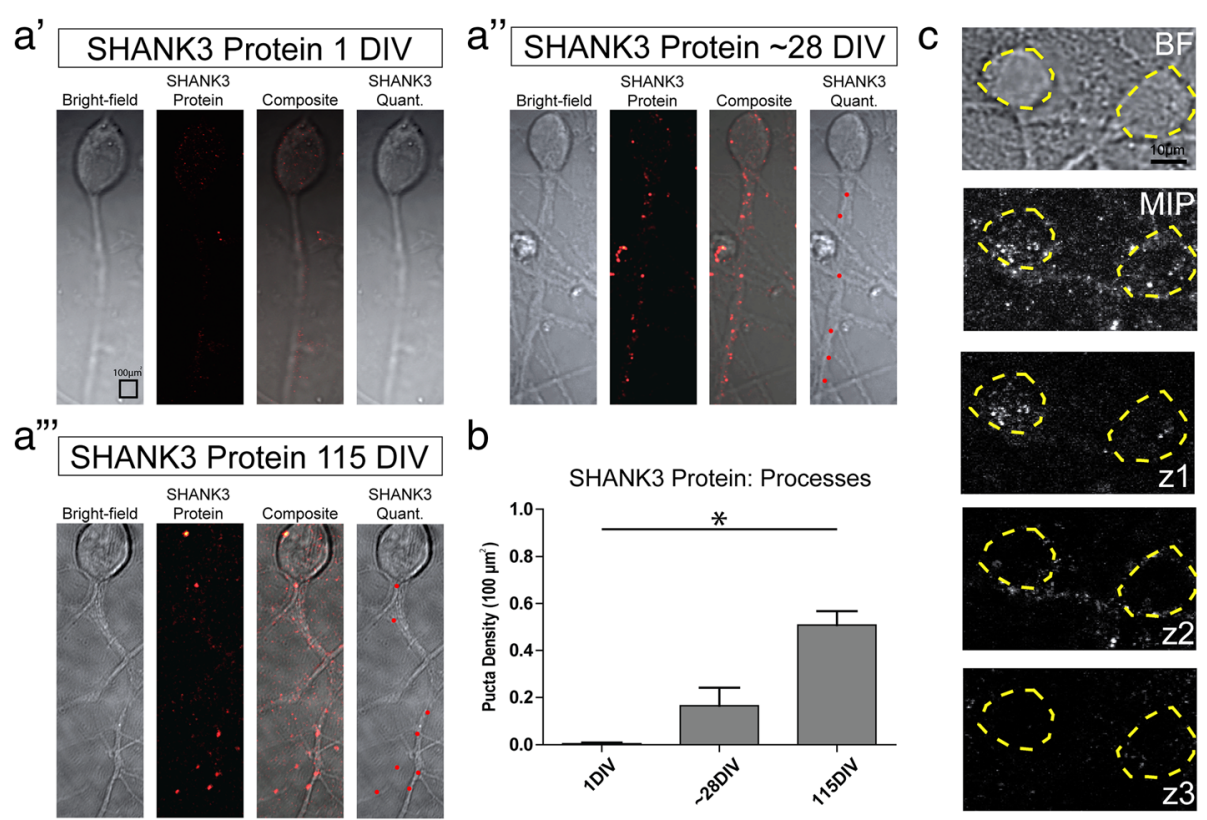

Fig. 3 SHANK3 protein expression increases with developmental age. a SHANK3 protein identified through immunofluorescence labelling. For each panel, left to right: bright-field image (BF) of representative hiPSC-derived neuron, SHANK3 protein immunofluorescence image, composite immunofluorescence and BF image, and SHANK3 protein puncta selected through automated quantification analysis. Images for (a') 1 day in vitro (DIV) $(n=3),\left(a^{\prime \prime}\right) 28$ DIV $(n=4)$ and (a"') 115 DIV $(n=5)$. b SHANK3 protein puncta per $100 \mu m^{2}$. Error bars indicate standard error of mean. *Kruskal-Wallis test $p<0.005$ at 1 DIV vs 115 DIV. c Z-stack demonstrates SHANK3 protein only present on outside and not within cell body of hiSPC-derived neurons as seen in maximum image projection (MIP). Z-stack images taken at $3.0 \mu \mathrm{m}$ spacing. Yellow dashed lines surround neuronal cell body. SHANK3 SH3 and multiple ankyrin repeat domains 3 


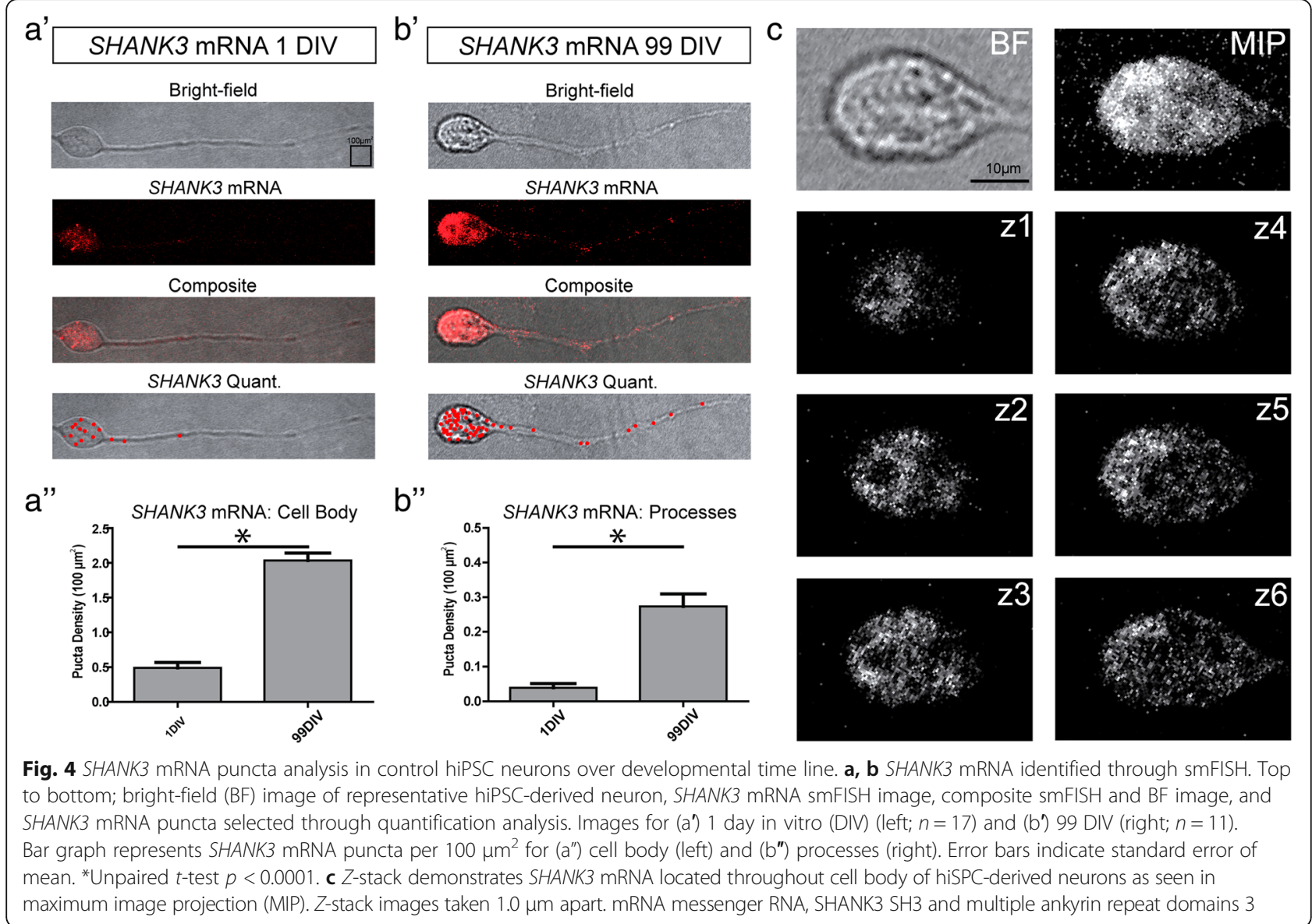

reduction in SHANK3 mRNA levels has been described previously in iPSC-derived neurons from patients with PMS using qRT-PCR [12], but their specific localization was not addressed. We used an hiPSC line generated from a 4-year-old male, diagnosed with ASD and developmental delay but not PMS, with a SHANK3 gene deletion starting at the third intron and continuing just beyond the end of the gene on chromosome 22q [19]. We differentiated cortical neurons from the patient line and a control male hiPSC line, and examined SHANK3 mRNA numbers and location at 53 DIV using smFISH. $\mathrm{SHANK3}^{+/-}$patient hiPSC neurons exhibited almost a $50 \%$ reduction in SHANK3 mRNA density within neuronal processes when compared with control $\left(\mathrm{SHANK}^{+/-}\right.$ patient mean mRNA density $=0.077$ puncta $/ 100 \mu \mathrm{m}^{2}(n=$ 20 ), control mean $=0.132$ puncta $/ 100 \mu \mathrm{m}^{2}(n=16) ; p=$ 0.0104, unpaired $t$ test) (Fig. 5a), while no differences were observed at the cell body $\left(\right.$ SHANK $^{+/-}$patient mean $=$ 0.794 puncta $/ 100 \mu^{2} \quad(n=20)$, control mean $=0.7624$ puncta/100 $\left.\mu \mathrm{m}^{2}(n=16)\right)$ (Fig. 5b).

\section{Discussion}

The idea that mRNA may be translated locally within dendrites of neurons grew from the visualization of synapse-associated polyribosome complexes (SPRCs) [25]. In-situ hybridization studies subsequently demonstrated the presence of specific mRNAs in neuronal dendrites [26] or dendrite-rich brain regions [27]. This profoundly changed the then dominant view that both transcription and translation occurred within the cell body [28]. Recent studies have shown upwards of over 2500 different mRNA transcripts locally translated within dendrites and axons of rat hippocampal neurons [13]. RNA binding proteins (RBPs) are thought to regulate the localization and translation of mRNA within dendrites by binding to the untranslated ( $3^{\prime}$-UTR and / or $5^{\prime}$-UTR) or coding regions [29]. Local translation in neuronal dendrites is believed to be important for synaptic modification, long-term potentiation (LTP) and long-term depression (LTD) [25, 30, 31]. Here we performed single-molecule fluorescence in-situ hybridization (smFISH) to label mRNA coding for the autism-risk gene SHANK3, and establish a protocol for puncta quantification. smFISH provides a higher sensitivity in molecular analysis and gene expression compared to traditional techniques, a level of sensitivity that has been lacking in hiPSC-derived lineages.

SHANK3 protein expression was quantified within our hiPSC-derived neurons to outline a developmental time 
a
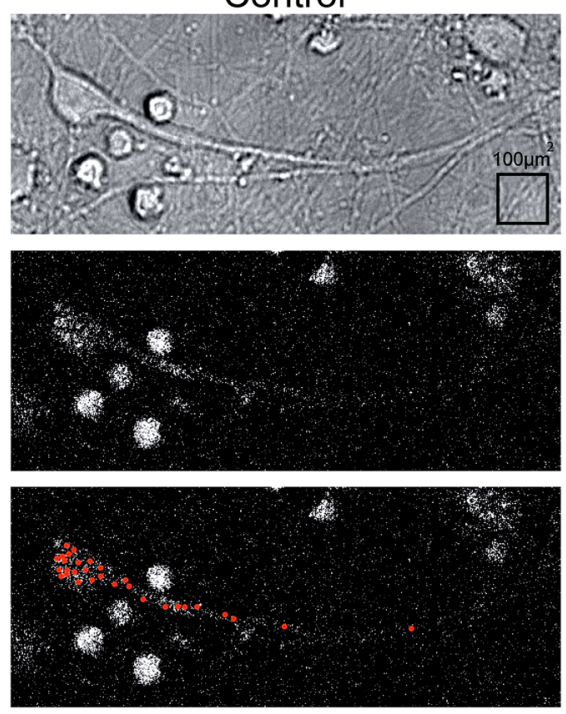

b

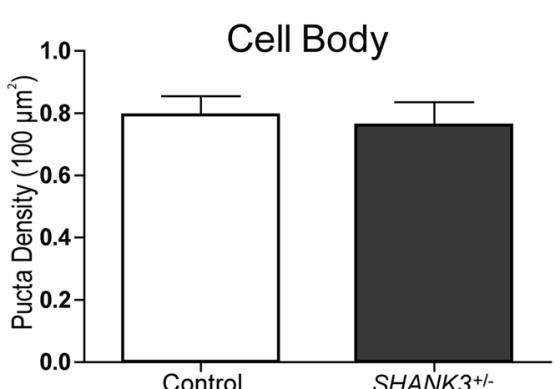

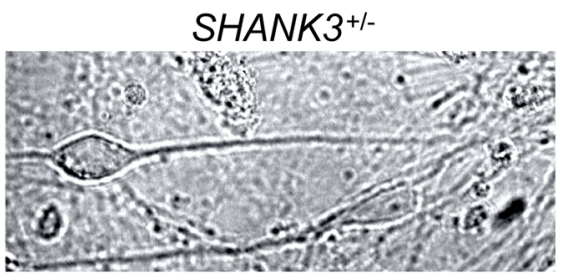
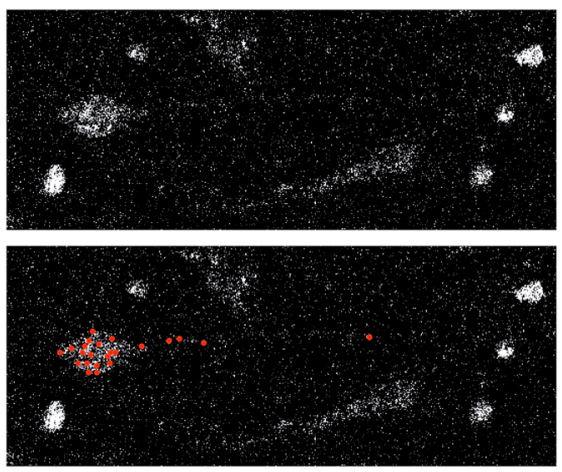

C

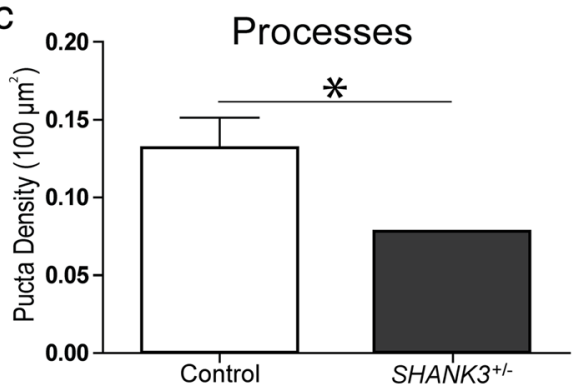

Fig. 5 SHANK3 mRNA expression in SHANK3 ${ }^{+/-}$male with ASD shows reduction restricted to processes. a Top to bottom: bright-field image, smFISH maximal projections (MIP) and MIP with identified puncta superimposed; both control (left) and SHANK3 ${ }^{+/-}$heterozygous patient (right) hiPSC-derived cortical neurons, 53 DIV. b SHANK3 mRNA puncta per $100 \mu^{2}$ within cell body of control ( $\left.n=16\right)$ and SHANK3 ${ }^{+/-}$heterozygous patient $(n=20)$ hiPSC-derived cortical neurons. c SHANK3 mRNA puncta per $100 \mu \mathrm{m}^{2}$ within processes of control $(n=16)$ and SHANK3 ${ }^{+/-}$ heterozygous patient $(n=20)$ hiPSC-derived cortical neurons. ${ }^{*} p=0.0104$ (unpaired $t$ test). Errors bars indicate standard error of mean. SHANK3 $\mathrm{SH} 3$ and multiple ankyrin repeat domains 3

line for pre-synapse and post-synapse formation. An increase in SHANK3 mRNA in the neuronal processes was consistent with synapse formation and appears to be present in the processes before the formation of excitatory synapses. This direct visualization of individual SHANK3 mRNA confirms in human neurons previous findings from rodent models using conventional ISH [32] and high-resolution FISH [13], and supports the view that key synaptic genes such as SHANK3 are likely to undergo local translation in neuronal dendrites, similar to that seen in rodent models $[13,32]$.

Here we demonstrated almost a $50 \%$ decrease in SHANK3 mRNA in the processes of SHANK $3^{+/-}$hiPSC neurons. SHANK $3^{+/-}$hiPSC neurons were generated from a male patient with a deletion on chromosome $22 \mathrm{q}$ which begins at the third intron of SHANK3 and extends beyond the end of the gene. As our data are from only one individual, it will be important to identify whether similar changes are seen in other SHANK3 deletion patients. In addition, it would be interesting to compare SHANK3 haploinsufficiency in the absence of features of PMS, as studied here, with neurons from PMS patients. An overall reduction in SHANK3 mRNA levels has been described previously in iPSC-derived neurons from patients with PMS using qRT-PCR [12], but their specific localization within the neurons was not addressed. The reduction in mRNA numbers in dendrites may have implications for the local translation of SHANK3. This finding is relevant as local dendritic translation of neuronal and synaptic proteins is believed to be important for synapse formation and function $[25,30,31]$, both of which are often disrupted in disorders such as ASD [8,33]. Indeed, abnormalities of dendritic mRNA translation in the ASDassociated disorder Fragile X syndrome are thought to result in changes to synapse function and plasticity [34-36]. SHANK3 heterozygosity in human neurons has been shown to have multiple effects, including on synaptic number and function, neuronal morphology and intrinsic 
neuronal properties [11, 12, 21]. It would therefore be interesting in the future to examine whether, and to what extent, other mRNAs may exhibit differential localization.

\section{Conclusions}

The ability to perform smFISH in hiPSC-derived neurons to label single target mRNA molecules provides a powerful way to study gene expression at high resolution in human cells. Our results confirm that previous findings, indicating the highly penetrant ASD-associated gene SHANK3 is likely to undergo local dendritic translation in neurons, also hold true in human neurons. Further, we provide evidence that SHANK3 haploinsufficiency in human neurons may specifically affect mRNAs targeted to dendrites, although further studies will be needed to confirm to what extent this is seen in neurons from other individuals. Given the importance of local mRNA translation in synaptic function, this could represent a key early abnormality which merits further investigation.

\section{Abbreviations \\ ASD: Autism spectrum disorder; BDNF: Brain-derived neurotrophic factor; BSA: Bovine serum albumin; DAPI: 4',6-Diamidino-2-phenylindole, dihydrochloride; DAPT: N-((3,5-Difluorophenyl)acetyl)-L-alanyl-2-phenylglycine- 1,1-dimethylethyl ester; DIV: Days in vitro; DMEM: Dulbecco's modified Eagle's medium; hiPSC: Human inducible pluripotent stem cell; LTD: Long-term depression; LTP: Long-term potentiation; MAP2: Microtubule-associated protein 2; MIP: Maximum image projection; mRNA: Messenger RNA; PBS: Phosphate- buffered saline; PDL: Poly-D-lysine; PMS: Phelan-McDermid syndrome; ProSAP2: Proline-rich synapse-associated protein 2; GRT-PCR: Quantitative real- time polymerase chain reaction; RBP: RNA binding protein; ROCK: Rho kinase; SHANK3: SH3 and multiple ankyrin repeat domains 3; smFISH: Single-molecule fluorescence in-situ hybridization; SPRC: Synapse-associated polyribosome complex; SSC: Saline-sodium citrate; UTR: Untranslated region}

\section{Acknowledgements}

The authors thank Paulina Nowosiad for technical support.

\section{Funding}

The authors acknowledge financial support from the Innovative Medicines Initiative Joint Undertaking under grant agreement no. 115300, resources of which are composed of a financial contribution from the European Union's Seventh Framework Programme (FP7/2007-2013) and EFPIA companies' inkind contribution, a Medical Research Council 4-year PhD studentship to SET, the Mortimer D Sackler Foundation and the Sackler Institute for Translational Neurodevelopment (to RDT), a BBSRC project grant BB/P000479/1 (to LCA) and funding from the National Institute for Health Research (NIHR) Biomedical Research Centre for Mental Health at South London and Maudsley NHS Foundation Trust and Institute of Psychiatry, King's College London. This article presents independent research funded by the NIHR. The views expressed are those of the author(s) and not necessarily those of the NHS, the NIHR or the Department of Health.

\section{Availability of data and materials}

All data generated or analysed during this study are available from the corresponding author on reasonable request.

\section{Authors' contributions}

SET, RDT, JP and LCA conceived and designed the experiments. SET carried out the experiments. SET, RDT and LCA analysed the data. SET and LCA wrote the manuscript. All authors read, commented on and approved the final manuscript.

\section{Ethics approval and consent to participate}

The work presented in this study did not require formal ethical approval. All human iPSC lines were originally obtained with ethical approval from the West
London \& GTAC NRES Committee (REC reference 14/LO/0010) and signed consent was obtained in all cases. All animal work was done under Schedule 1 of the Animal (Scientific Procedures) Act 1986 (UK) by trained personnel in accordance with $\mathrm{KCL}$ guidelines and with regard to the $3 R s$, which does not require ethical approval by a specific body, and no licensed procedures were carried out.

\section{Consent for publication}

Not applicable.

\section{Competing interests}

The authors declare that they have no competing interests.

\section{Publisher's Note}

Springer Nature remains neutral with regard to jurisdictional claims in published maps and institutional affiliations.

\section{Author details}

${ }^{1}$ Centre for Developmental Neurobiology, Institute of Psychiatry, Psychology and Neuroscience, King's College London, London SE1 1UL, UK. ${ }^{2}$ MRC Centre for Neurodevelopmental Disorders, King's College London, London, UK. ${ }^{3}$ Department of Basic and Clinical Neuroscience, Institute of Psychiatry, Psychology and Neuroscience, King's College London, London SE5 8AF, UK.

Received: 18 October 2017 Revised: 13 June 2018

Accepted: 16 July 2018 Published online: 31 July 2018

\section{References}

1. Betancur C, Buxbaum JD. SHANK3 haploinsufficiency: a "common" but underdiagnosed highly penetrant monogenic cause of autism spectrum disorders. Mol Autism. 2013;4:17.

2. Bonaglia MC, Giorda R, Beri S, De Agostini C, Novara F, Fichera M, Grillo L, Galesi O, Vetro A, Ciccone R. Molecular mechanisms generating and stabilizing terminal 22q13 deletions in 44 subjects with Phelan/McDermid syndrome. PLoS Genet. 2011;7:e1002173.

3. Sarasua SM, Dwivedi A, Boccuto L, Rollins JD, Chen C-F, Rogers RC, Phelan K, DuPont BR, Collins JS. Association between deletion size and important phenotypes expands the genomic region of interest in Phelan-McDermid syndrome (22q13 deletion syndrome). J Med Genet. 2011;48(11):761-6. https://doi.org/10.1136/jmedgenet-2011-100225.

4. Sakai Y, Shaw CA, Dawson BC, Dugas DV, Al-Mohtaseb Z, Hill DE, Zoghbi HY. Protein interactome reveals converging molecular pathways among autism disorders. Sci Transl Med. 2011:3:86ra49.

5. Jiang Y-h, Ehlers MD. Modeling autism by SHANK gene mutations in mice. Neuron. 2013:78:8-27.

6. Kelleher RJ III, Geigenmüller U, Hovhannisyan H, Trautman E, Pinard R, Rathmell B, Carpenter R, Margulies D. High-throughput sequencing of mGluR signaling pathway genes reveals enrichment of rare variants in autism. PLoS One. 2012;7:e35003.

7. Boccuto L, Lauri M, Sarasua SM, Skinner CD, Buccella D, Dwivedi A, Orteschi $D$, Collins JS, Zollino M, Visconti P. Prevalence of SHANK3 variants in patients with different subtypes of autism spectrum disorders. Eur J Hum Genet. 2012;21:310-6.

8. Durand CM, Betancur C, Boeckers TM, Bockmann J, Chaste P, Fauchereau F, Nygren G, Rastam M, Gillberg IC, Anckarsäter H. Mutations in the gene encoding the synaptic scaffolding protein SHANK3 are associated with autism spectrum disorders. Nat Genet. 2007;39:25-7.

9. Sheng M, Kim E. The Shank family of scaffold proteins. J Cell Sci. 2000;113: $1851-6$.

10. Monteiro P, Feng G. SHANK proteins: roles at the synapse and in autism spectrum disorder. Nat Rev Neurosci. 2017;18(3):147-57. https://doi.org/10. 1038/nrn.2016.183.

11. Yi F, Danko T, Botelho SC, Patzke C, Pak C, Wernig M, Südhof TC. Autismassociated SHANK3 haploinsufficiency causes Ih channelopathy in human neurons. Science. 2016;352(6286):aaf2669. https://doi.org/10.1126/science. aaf2669.

12. Shcheglovitov A, Shcheglovitova O, Yazawa M, Portmann T, Shu R, Sebastiano V, Krawisz A, Froehlich W, Bernstein JA, Hallmayer JF. SHANK3 and IGF1 restore synaptic deficits in neurons from 22q13 deletion syndrome patients. Nature. 2013;503:267-71. 
13. Cajigas IJ, Tushev G, Will TJ, Fuerst N, Schuman EM. The local transcriptome in the synaptic neuropil revealed by deep sequencing and high-resolution imaging. Neuron. 2012;74:453-66.

14. Epstein I, Tushev G, Will TJ, Vlatkovic I, Cajigas IJ, Schuman EM. Alternative polyadenylation and differential expression of shank mRNAs in the synaptic neuropil. Philos Trans R Soc Lond B Biol Sci. 2014;369:20130137.

15. Trcek T, Chao JA, Larson DR, Park HY, Zenklusen D, Shenoy SM, Singer RH. Single-mRNA counting using fluorescent in situ hybridization in budding yeast. Nat Protoc. 2012;7:408-19.

16. Itzkovitz S, Lyubimova A, Blat IC, Maynard M, Van Es J, Lees J, Jacks T, Clevers $\mathrm{H}$, Van Oudenaarden A. Single-molecule transcript counting of stem-cell markers in the mouse intestine. Nat Cell Biol. 2012;14:106-14

17. Urbanek MO, Krzyzosiak WJ. RNA FISH for detecting expanded repeats in human diseases. Methods. 2016;98:115-23.

18. Cabili MN, Dunagin MC, McClanahan PD, Biaesch A, Padovan-Merhar O, Regev A, Rinn JL, Raj A. Localization and abundance analysis of human IncRNAs at single-cell and single-molecule resolution. Genome Biol. 2015;16:1.

19. Cocks G, Curran S, Gami P, Uwanogho D, Jeffries AR, Kathuria A, Lucchesi W, Wood V, Dixon R, Ogilvie C. The utility of patient specific induced pluripotent stem cells for the modelling of autistic spectrum disorders. Psychopharmacology. 2014;231:1079-88.

20. Shi Y, Kirwan P, Livesey FJ. Directed differentiation of human pluripotent stem cells to cerebral cortex neurons and neural networks. Nat Protoc. 2012; 7:1836-46.

21. Kathuria A, Nowosiad P, Jagasia R, Aigner S, Taylor RD, Andreae LC, Gatford NJF, Lucchesi W, Srivastava DP, Price J. Stem cell-derived neurons from autistic individuals with SHANK3 mutation show morphogenetic abnormalities during early development. Mol Psychiatry. 2018;23(3):735-46. https://doi.org/10.1038/mp.2017.185.

22. Kaech S, Banker G. Culturing hippocampal neurons. Nat Protoc. 2006;1:2406-15.

23. Andreae $L C$, Fredj NB, Burrone J. Independent vesicle pools underlie different modes of release during neuronal development. J Neurosci. 2012; 32:1867-74.

24. Mueller F, Senecal A, Tantale K, Marie-Nelly H, Ly N, Collin O, Basyuk E, Bertrand E, Darzacq X, Zimmer C. FISH-quant: automatic counting of transcripts in 3D FISH images. Nat Methods. 2013;10:277-8.

25. Steward O, Levy WB. Preferential localization of polyribosomes under the base of dendritic spines in granule cells of the dentate gyrus. J Neurosci. 1982;2:284-91.

26. Kleiman R, Banker G, Steward O. Differential subcellular localization of particular mRNAs in hippocampal neurons in culture. Neuron. 1990;5:821-30.

27. Burgin KE, Waxham MN, Rickling S, Westgate SA, Mobley WC, Kelly PT. In situ hybridization histochemistry of $\mathrm{Ca} 2+/$ calmodulin-dependent protein kinase in developing rat brain. J Neurosci. 1990;10:1788-98.

28. Holt CE, Schuman EM. The central dogma decentralized: new perspectives on RNA function and local translation in neurons. Neuron. 2013;80:648-57.

29. Liu-Yesucevitz L, Bassell GJ, Gitler AD, Hart AC, Klann E, Richter JD, Warren ST, Wolozin B. Local RNA translation at the synapse and in disease. J Neurosci. 2011;31:16086-93.

30. Schuman EM, Dynes JL, Steward O. Synaptic regulation of translation of dendritic mRNAs. J Neurosci. 2006;26:7143-6.

31. Gardiol A, Racca C, Triller A. Dendritic and postsynaptic protein synthetic machinery. J Neurosci. 1999;19:168-79.

32. Böckers TM, Segger-Junius M, Iglauer P, Bockmann J, Gundelfinger ED, Kreutz MR, Richter D, Kindler S, Kreienkamp H-J. Differential expression and dendritic transcript localization of shank family members: identification of a dendritic targeting element in the 3' untranslated region of Shank1 mRNA. Mol Cell Neurosci. 2004;26:182-90.

33. Gilman SR, lossifov I, Levy D, Ronemus M, Wigler M, Vitkup D. Rare de novo variants associated with autism implicate a large functional network of genes involved in formation and function of synapses. Neuron. 2011;70:898-907.

34. Dictenberg JB, Swanger SA, Antar LN, Singer RH, Bassell GJ. A direct role for FMRP in activity-dependent dendritic mRNA transport links filopodial-spine morphogenesis to fragile X syndrome. Dev Cell. 2008;14:926-39.

35. Bassell GJ, Warren ST. Fragile $X$ syndrome: loss of local mRNA regulation alters synaptic development and function. Neuron. 2008;60:201-14.

36. Irwin SA, Patel B, Idupulapati M, Harris JB, Crisostomo RA, Larsen BP, Kooy F, Willems PJ, Cras P, Kozlowski PB. Abnormal dendritic spine characteristics in the temporal and visual cortices of patients with fragile-X syndrome: a quantitative examination. Am J Med Genet. 2001:98:161-7.

\section{Ready to submit your research? Choose BMC and benefit from:}

- fast, convenient online submission

- thorough peer review by experienced researchers in your field

- rapid publication on acceptance

- support for research data, including large and complex data types

- gold Open Access which fosters wider collaboration and increased citations

- maximum visibility for your research: over $100 \mathrm{M}$ website views per year

At $\mathrm{BMC}$, research is always in progress.

Learn more biomedcentral.com/submissions 